\title{
DETERMINATION OF THE POSITION AND SIZE OF DG IN UNBALANCED RADIAL DISTRIBUTION SYSTEM USING COYOTE ALGORITHM
}

\author{
ANH VIET TRUONG ${ }^{1}$, TRIEU NGOC TON ${ }^{1,2}$ \\ ${ }^{1}$ HCMC University of Technology and Education, Ho Chi Minh City \\ ${ }^{2}$ Thu Duc College of Technology, Ho Chi Minh City \\ trieutn.ncs@hcmute.edu.vn
}

\begin{abstract}
This paper proposes a method to optimize the position and size of distributed generations (DGs) based on Coyote algorithm (COA) to minimize the power loss of the radial unbalanced distribution system (URDS). The proposed COA method is a recently developed meta heuristic algorithm, inspired by the social life of the North American wolf. COA does not need to use control parameters in the application process for the optimization problem. The proposed method, using COA to optimize the installation of DG for URDS in order to bring about the minimum effective power loss. The results of the proposed method were tested on URDS 25 buses and compared with another method, showing its effectiveness against URDS.
\end{abstract}

Keywords. Distributed Generations; Coyote Algorithm; Unbalanced Radial Distribution System; Power Loss.

\section{INTRODUCTION}

Distributed generations (DGs) are linked to the electric distribution system (EDS) because the economic benefits and energy security are enormous. Determining the location and size of DGs is appropriate according to the target so that EDS can operate flexibly and exploit the maximum potential benefits of DGs with minimum cost but must satisfy technical limitations and optimization. economic targets. The problem of determining position and size of DGs is well studied, but focused on balanced EDS. In fact, EDS operates almost in unbalanced conditions with huge power losses. Currently, there are many methods to reduce power loss on URDS, of which DG installation is an effective solution as well as exploiting the existing potential of distributed generations. Therefore, the problem of position optimization, the size of DGs to minimize power loss in unbalanced EDS is very important [1], [2].

To optimize the position and size of DGs in EDS, there is a classical and artificial method. The proposed methods are linear programming (LP), non-linear programming (NLP) [3], mixed integer NLP (MINLP) [4], ordinal optimization (OO) [5]. In [3]-[5] often the optimal results are slow convergence or fall into local extremes. Several hybrid search methods for position and size optimization of DGs yield fast and global convergence optimization results such as gene algorithm (GA) [6], particle swarm optimiza-tion algorithm (PSO) [7], salp swarm algorithm (SSA) [8]. In [6]-[8] proposed a new technique to optimize DGs with the goal of minimizing power loss. These methods have shown accurate results and converge quickly but only apply to EDS equilibrium. In [9]-[16] presented different techniques to optimize the position and size of DGs in the unbalanced radial distribution system (URDS) to reduce power loss. These methods calculate based on losses on phases or voltage indicators without considering neutral wires and the proposed algorithm is not completely optimal.

The DG optimization problem on URDS has many methods to perform. However, with the current constraints, the meta hueristic method is exploited in the optimization problem. With the current meta hueristic algorithms used are mainly based on natural and social ideas. Inside, Coyote Algorithm (COA) was developed based on the idea of social behavior of wolves [17]. In [18], the COA used for the position and size problem on the balanced EDS showed its effectiveness. However, its effectiveness for the URDS problem is an issue that needs to be considered. In this paper, COA is used to optimize the position and size of DG to reduce power loss on URDS. COA efficiency is assessed on 25 bus URDS. The results are compared with the method in [16], which shows the results of the proposed method.

\section{PROBLEM FORMULATION}

In a three phase unbalanced load flow of distribution system the following each individual system component is mathematically represented by models that approximate their physical behaviour. Network 
components include the distribution lines, shunt capacitors, cogeneration and transformers. In the power flow calculation, components are modeled by their equivalent circuits in terms of inductance, capacitance, resistance and injected current [16].

On URDS, the neutral wire will have $\mathrm{I}_{\mathrm{N}}$, Fig 1. For $\mathrm{P}_{\mathrm{A}}, \mathrm{P}_{\mathrm{B}}, \mathrm{P}_{\mathrm{C}}$ respectively, is the active power of phase $\mathrm{A}$, $\mathrm{B}, \mathrm{C}$. Then the power $\mathrm{P}$ of the three-phase circuit as (1).

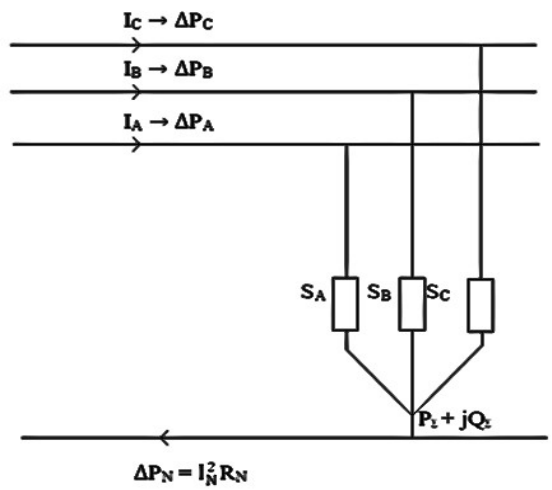

Fig 1. Basic URDS model

$\mathrm{P}=\mathrm{P}_{\mathrm{A}}+\mathrm{P}_{\mathrm{B}}+\mathrm{P}_{\mathrm{C}}=\mathrm{U}_{\mathrm{A}} \mathrm{I}_{\mathrm{A}} \cos \varphi_{\mathrm{A}}+\mathrm{U}_{\mathrm{B}} \mathrm{I}_{\mathrm{B}} \cos \varphi_{\mathrm{B}}+\mathrm{U}_{\mathrm{C}} \mathrm{I}_{\mathrm{C}} \cos \varphi_{\mathrm{C}}$

Balanced three phase power network: $\mathrm{U}_{\mathrm{A}}=\mathrm{U}_{\mathrm{B}}=\mathrm{U}_{\mathrm{C}}=\mathrm{U}_{\mathrm{p}}$ và $\mathrm{I}_{\mathrm{A}}=\mathrm{I}_{\mathrm{B}}=\mathrm{I}_{\mathrm{C}}=\mathrm{I}_{\mathrm{p}}$

With: $\cos \varphi_{\mathrm{A}}=\cos \varphi_{\mathrm{B}}=\cos \varphi_{\mathrm{C}}=\cos \varphi$

$\mathrm{P}=3 \mathrm{U}_{\mathrm{p}} \mathrm{I}_{\mathrm{p}} \cos \varphi=3 \mathrm{I}_{\mathrm{p}}^{2} \mathrm{R}_{\mathrm{p}}$

With: $\cos \varphi_{\mathrm{A}}=\cos \varphi_{\mathrm{B}}=\cos \varphi_{\mathrm{C}}=\cos \varphi_{\mathrm{A}} \mathrm{S}_{\mathrm{A}}=\mathrm{P}_{\mathrm{A}}+\mathrm{j} \mathrm{Q}_{\mathrm{A}} ; \mathrm{S}_{\mathrm{B}}=\mathrm{P}_{\mathrm{B}}+\mathrm{j} \mathrm{Q}_{\mathrm{B}} ; \mathrm{S}_{\mathrm{C}}=\mathrm{P}_{\mathrm{C}}+\mathrm{j} \mathrm{Q}_{\mathrm{C}}$.

From the power conversion vector diagram in Fig 2, the relationship between the three phases A, B and $\mathrm{C}$ we have:

$\mathrm{P}_{\Sigma}=\mathrm{P}_{\mathrm{A}}-\mathrm{P}_{\mathrm{B}} \frac{1}{2}-\mathrm{P}_{\mathrm{C}} \frac{1}{2}-\mathrm{Q}_{\mathrm{B}} \frac{\sqrt{3}}{2}+\mathrm{Q}_{\mathrm{C}} \frac{\sqrt{3}}{2}$

$\mathrm{Q}_{\Sigma}=\mathrm{Q}_{\mathrm{A}}-\mathrm{Q}_{\mathrm{B}} \frac{1}{2}-\mathrm{Q}_{\mathrm{C}} \frac{1}{2}+\mathrm{P}_{\mathrm{B}} \frac{\sqrt{3}}{2}-\mathrm{P}_{\mathrm{C}} \frac{\sqrt{3}}{2}$

The objective function is:

$\sum P_{\text {loss }}=\Delta \mathrm{P}_{\mathrm{A}}+\Delta \mathrm{P}_{\mathrm{B}}+\Delta \mathrm{P}_{\mathrm{C}}+\Delta \mathrm{P}_{\mathrm{N}}$

With: $\Delta \mathrm{P}_{\mathrm{N}}=\frac{\mathrm{P}_{\Sigma}^{2}+\mathrm{Q}_{\Sigma}^{2}}{\mathrm{U}^{2}} \mathrm{R}_{\mathrm{N}}$

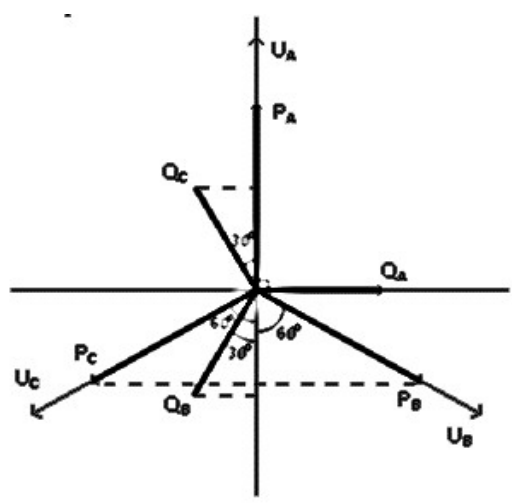

Fig 2. Power conversion scheme

The objective function of the problem determines DG position and size on URDS:

$$
f=\min \left(\sum P_{\text {loss }}\right)
$$

When installing DGs on URDS, the sizes of DGs are within the limits:

- Power balance: The sum of output power of the slack bus and the DGs must be equal to the sum of loads and power loss in the URDS.

- Limits of nodes' voltage and branches' current: 


$$
\left\{\begin{array}{l}
\mathrm{V}_{\min }^{\lim } \leq V_{i} \leq \mathrm{V}_{\text {max }}^{\text {lim }} ; i=1,2, \cdots, N_{\text {bus }} \\
L C F_{i} \leq L C F_{\text {max }, i}^{\text {lim }} ; i=1,2, \cdots, N_{\text {branch }}
\end{array}\right.
$$

Where LCF is load carrying factor of the branch ith.

- Power limits of DGs:

$P_{D G, i, \min } \leq P_{D G, i} \leq P_{D G, i, \max } ; i=1,2, \cdots, N_{D G}$

During the installation of DGs on URDS, it is necessary to satisfy the conditions of voltage and current binding within the permissible limits. Therefore, the adaptive function of the problem is described as follows:

$$
f i t=f+K \cdot\left[\max \left(\mathrm{V}_{\min }^{l i m}-V_{\min }, 0\right)+\max \left(V_{\max }-\mathrm{V}_{\max }^{l i m}, 0\right)+\max \left(L C F_{\max }-\mathrm{LCF}_{\max }^{l i m}, 0\right)\right] \text { (10) }
$$

Where: fit is the value of the adaptive function; $\mathrm{K}$ is the penalty factor for violating the voltage and current constraints; $V_{\min }^{\text {lim }}$ and $V_{\min }$ are the lowest allowable voltage limits and the smallest voltage amplitude; $V_{\max }^{l i m}$ and $V_{\max }$ are the maximum permissible voltage limits and maximum voltage amplitude; $L C F_{\text {max }}$ and $\mathrm{LCF}_{\text {max }}^{\lim }$ are the largest load factors in URDS and the allowable load factors.

\section{PROPOSED METHOD}

\subsection{The COA algorithm}

The COA was developed based on the idea of the social life of wolves [17]. Unlike other metaphysical methods, COAs do not need control parameters. This helps to increase the performance stability of the COA for position and size optimization of DG. The COA algorithm uses the wolf population, in which the population is divided into groups and the social condition of each wolf is considered to be an optional solution to the optimal problem. New candidate solutions are created based on the interaction between wolves in each group and the interaction between population groups.

1. Renew the social condition of coyotes in each group. In each small group of coyotes, the behavior of each coyote depends on the leader of the group. In addition, each group usually has its own characteristics compared to other groups. Based on this metaphor, the new solutions in COA is renewed as bellows: In the group gth, the coyote having the best adaptive function value is chosen as an alpha $\left(\mathrm{al}^{\mathrm{g}}\right)$. Futhermore, the culture tendency $\left(\mathrm{ct}^{\mathrm{g}}\right)$ of the group is determined by the median social condition of the group's coyotes. Then, new social condition of each coyote is generate as follows:

$$
\mathrm{n}_{-} \mathrm{sc}_{c}^{g}=\mathrm{sc}_{c}^{g}+r_{1} \cdot\left(a l^{g}-\mathrm{sc}_{1}^{g}\right)+r_{2} \cdot\left(c t^{g}-\mathrm{sc}_{2}^{g}\right)
$$

Where $\mathrm{n}_{-} \mathrm{sc}_{c}^{g}$ and $\mathrm{sc}_{c}^{g}$ are new and current social condition of the coyote cth in the group gth. $\mathrm{sc}_{1}^{g}$ and $\mathrm{sc}_{2}^{g}$ are social condition of two coyotes selected randomly in the group gth. $r_{1}$ and $r_{2}$ are random number in range of $[0,1]$.

2. Be born the new coyote for replacing the old coyote in each gorup. In the group, the old coyote having the worst social condition will be died and replaced by a puppy which is born as follows:

$$
x_{\text {puppy }, j}^{g}=\left\{\begin{array}{l}
x_{1, j}^{g} ; r_{3, j}<k_{1} \\
x_{2, j}^{g} ; r_{3, j}<k_{1}+k_{2} \\
x_{r, j}^{g} ; \text { otherwise }
\end{array}\right.
$$

Where $x_{\text {puppy,j }}^{g}(\mathrm{j}=1,2, \ldots, \mathrm{D})$ is the variable $\mathrm{jth}$ of the vector solution of the puppy's social condition. $\mathrm{D}$ is the dimension of the problem. $x_{1, j}^{g}$ and $x_{2, j}^{g}$ are the variable of the two solution chosen randomly in the group. $r_{3, \mathrm{j}}$ is a random number in range of $[0,1] \cdot x_{r, j}^{g}$ is a random variable. $k_{1}$ and $k_{2}$ are the probability of scatter and association which guides the cultural diversity of the coyotes from the group.

$$
\left\{\begin{array}{l}
k_{1}=1 / D \\
k_{2}=\left(1-k_{1}\right) / 2
\end{array}\right.
$$

3. Interchange coyotes between the groups. Although living in groups, some individuals sometimes leave the group to live alone or join another group. With this feature, to diversify in the process of creating new solutions, among population groups, there is the exchange of wolves. The probability $\left(P_{l}\right)$ of a wolf leaving one group to join another and vice versa is determined:

$$
P_{l}=0.005 \times N_{c}^{2}
$$

Where $N_{\mathrm{c}}$ is the number of coyotes in the group. 


\subsection{COA for the problem of optimal position and size of DG}

COA is applied to optimize the position and size of DG to minimize power loss in URDS. General principles of COA are expressed in the following steps:

- Step 1: Select the parameters of COA including number of group $\left(N_{\mathrm{g}}\right)$ and group size $\left(N_{\mathrm{c}}\right)$ and the maximum number of generations $\left(G_{\max }\right)$.

- Step 2: The initial population of coyotes is represent as $\operatorname{sc}_{c}^{g}=\left[L_{1, c}^{g}, \ldots, L_{N_{D G}, c}^{g}, P_{1, c}^{g}, \ldots, P_{N_{D G}, c}^{g}\right]$ with $g=$ $1,2, \ldots, N_{g}$ and $c=1,2, \ldots, N_{c}$. In which, $L_{k, c}^{g}$ and $P_{k, c}^{g}$ represents for position and size of the DG kth. The position and size of DG are initialized as follows:

$$
\begin{aligned}
& L_{k, c}^{g}=\operatorname{round}\left[2+\operatorname{rand}(0,1) \cdot\left(N_{b u s}-2\right)\right] \\
& \quad P_{k, c}^{g}=\operatorname{rand}(0,1) \cdot\left(P_{k, \text { max }}^{g}-P_{k, \text { min }}^{g}\right)+P_{k, \text { min }}^{g}
\end{aligned}
$$

Where $P_{k, \max }^{g}$ and $P_{k, \min }^{g}$ are the maximum and minimum power of the DG kth.

- Step 3: The initialized population is evaluated based on a fitness function determined as follows:

$f i t=f+K \cdot\left[\max \left(\mathrm{V}_{\min }^{l i m}-V_{\min }, 0\right)+\max \left(V_{\max }-\mathrm{V}_{\max }^{l i m}, 0\right)+\max \left(L C F_{\max }-\mathrm{LCF}_{\max }^{\lim }, 0\right)\right]$

Where $\mathrm{K}$ is penalty factors set to $1000 . V_{\min }$ and $V_{\max }$ are the minimum and maximum voltage. $L C F_{\max }$ is the maximum load carrying factor.

- Step 4: The main loop, the outer loop from step 4 to step 8 is continued execution until the pre-created value is reached. The inner loop (steps 5 through 6) continues until the last group of the population is reached.

- Step 5: Renew the social condition of coyotes in each group. For each group of coyotes, select the alpha coyote and determine the median of all coyotes. Generate new social condition of each coyote using (10). The fitness value is calculated for the social condition. If the social condition is better than the previous one, it will replace the previous one.

- Step 6: Replace the old coyote by the new coyote in the group. Generate the coyote puppy using (11). The fitness value of the social of the coyote puppy is calculated. If the social condition is better than the worst social condition in the group, it will replace the worst social condition. Go to step 5 if the current group is not the last group of the population. Otherwise, go to the next step.

- Step 7: Interchange a coyote between the groups. If rand $(0,1)<P_{l}$, two groups of coyotes in the population are randomly selected for exchanging coyotes. In the selected groups, two coyotes are randomly chosen to exchange. The result is that position of the selected coyote in the first group is replaced by the selected coyote of the second group and position of the selected coyote of the second group is replaced by the selected coyote of the first group.

- Step 8: In the proposed COA method, the stopping criterion is based on maximum number of generations. The algorithm is terminated as the generation reaches to the maximum value. Otherwise, return to step 4 to start the next generation. As the maximum number of generations reaches, the best social condition of all coyotes in the population is considered as the optimal solution of the problem of optimal position and size of DG.

\section{NUMERICAL RESULTS}

The proposed COA method is tested on URDS with a voltage of $4.16 \mathrm{kV}, 25$-bus, Fig 3. Line and load data as in reference [16]. The initial power loss of the system is $150.12 \mathrm{~kW}$ with the lowest voltages in phases A, B \& C respectively $0.9284,0.9284,0.9366$ p.u at node 12 . The control parameters of the COA set for the system include: The number of groups and the number of individuals in each group of times are selected as 5 and 6 . The maximum number of loops is selected as 300 . 


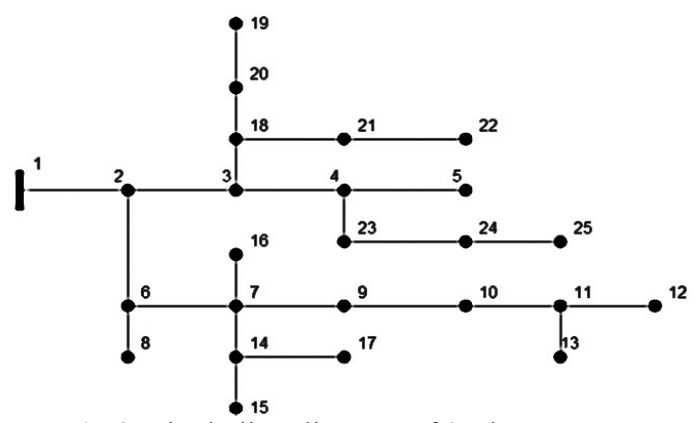

Fig 3. Single line diagram of 25-bus URDS

Table 1. Test results before and after installation of DG

\begin{tabular}{|c|c|c|c|}
\hline \multirow{2}{*}{ Description } & \multirow{2}{*}{$\begin{array}{c}\text { Before } \\
\text { DG }\end{array}$} & $\begin{array}{c}|c| \\
\text { Placement }\end{array}$ & After DG Placement \\
\cline { 3 - 4 } & - & 13 & DG - COA \\
\hline DG position & - & $215 \mathrm{~kW}$ & $223 \mathrm{~kW}$ \\
& & at $0.85 \mathrm{p} . \mathrm{f}$ & at 0.87 p.f \\
\hline DG size & $0.9284(\mathrm{~A})$ & $0.9504(\mathrm{~A})$ & $0.9542(\mathrm{~A})$ \\
& $0.9284(\mathrm{~B})$ & $0.9511(\mathrm{~B})$ & $0.9552(\mathrm{~B})$ \\
\hline Minimum Voltage & $0.9366(\mathrm{C})$ & $0.9557(\mathrm{C})$ & $0.9598(\mathrm{C})$ \\
\hline Total power loss $(\mathrm{kW})$ & 150.12 & 90.44 & 86.25 \\
\hline Total power loss reduction $(\%)$ & - & 39.76 & 42.55 \\
\hline
\end{tabular}

After using the COA algorithm to optimize the position and size of $1 \mathrm{DG}$, the results show that DG is located at node 13 with size of $215 \mathrm{~kW}$ at 0.87 lagging power factor. Table 1 shows a summary of the test results before and after placing the DG of the proposed method with the original and the method proposed in the reference [16]. When connected with DG, the total loss of the whole system is $86.25 \mathrm{~kW}$ with the lowest voltage in phases is $0.9542,0.9552,0.9598 \mathrm{p} . \mathrm{u}$ at node 12 . From the results, the total power loss across the system decreased from $150.12 \mathrm{~kW}$ to $86.25 \mathrm{~kW}$ and the voltage at node 12 was also improved in all three phases from $0.9284,0.9284,0.9366$ p.u to $0.9542,0.9552,0.9598$ p.u at node 12 . The results of the proposed method also show that the loss of active power is lower and the voltage is improved compared to the method in the reference [16]. In addition to reducing the power loss of the system, the voltage at all nodes is also improved, Fig 4. Figure 5 shows the convergence speed of the algorithm and the current on the branches of the 25 -node unbalanced distribution power system.



Fig 4. Voltage (p.u) for 25-bus URDS 

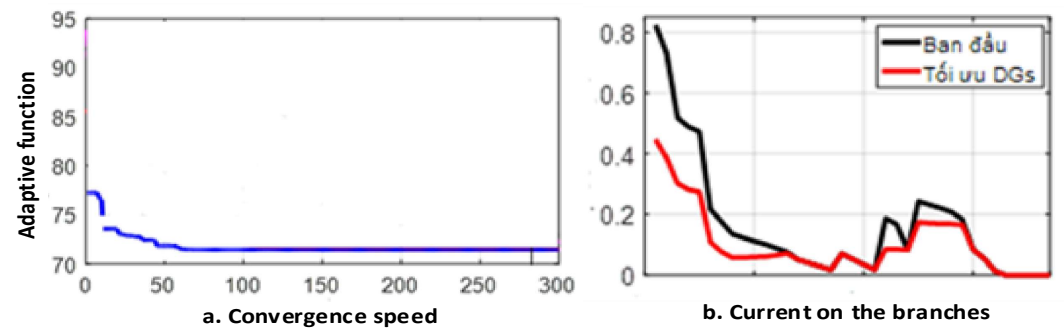

Fig 5. Convergence rate and current on the branches

\section{CONCLUSION}

This paper presents a method so that the position and size of DG on the distribution grid is not equal to the size of DG is balanced. From the data analyzed data with the location and size of DG shows that the effect of installing DG into the unbalanced grid has reduced the effective power loss of URDS as well as improved the voltage of buttons. The COA algorithm is applied to test the determination of the location and size of the DG on the unbalanced grid. The proposed method has been successfully applied to the 25 -node unbalanced distribution grid. The proposed method is applied as an effective method to optimize the position and size of DG in URDS.

\section{REFERENCES}

[1] R. H. A. Zubo, G. Mokryani, H. S. Rajamani, J. Aghaei, T. Niknam, and P. Pillai, 'Operation and planning of distribution networks with integration of renewable distributed generators considering uncertainties: A review', Renew. Sustain. Energy Rev., vol. 72, no. September, pp. 1177-1198, 2017.

[2] M. Kumawat, N. Gupta, N. Jain, and R. C. Bansal, 'Optimally Allocation of Distributed Generators in ThreePhase Unbalanced Distribution Network', Energy Procedia, vol. 142, pp. 749-754, 2017.

[3] A. Keane and M. O'Malley, 'Optimal allocation of embedded generation on distribution networks', IEEE Trans. Power Syst., vol. 20, no. 3, pp. 1640-1646, 2005.

[4] Y. M. Atwa, E. F. El-Saadany, M. M. A. Salama, and R. Seethapathy, 'Optimal renewable resources mix for distribution system energy loss minimization', IEEE Trans. Power Syst., vol. 25, no. 1, pp. 360-370, 2010.

[5] J. H. Teng, Y. H. Liu, C. Y. Chen, and C. F. Chen, 'Value-based distributed generator placements for service quality improvements', Int. J. Electr. Power Energy Syst., vol. 29, no. 3, pp. 268-274, 2007.

[6] A. Silvestri, A. Berizzi, and S. Buonanno, 'Distributed generation planning using genetic algorithms', Int. Conf. Electr. Power Eng. PowerTech Budapest 1999, p. 257, 1999.

[7] P. Kayal and C. K. Chanda, 'Placement of wind and solar based DGs in distribution system for power loss minimization and voltage stability improvement', Int. J. Electr. Power Energy Syst., vol. 53, pp. 795-809, 2013.

[8] K. S. Sambaiah and T. Jayabarathi, 'Optimal allocation of renewable distributed generation and capacitor banks in distribution systems using salp swarm algorithm', Int. J. Renew. Energy Res., vol. 9, no. 1, pp. 96107, 2019.

[9] A. Parizad, A. H. Khazali, and M. Kalantar, 'Unbalanced distribution network planning by sitting and sizing of distributed generation and harmonic filter due to losses and THD minimization', Int. Rev. Electr. Eng., vol. 5, no. 2, pp. 726-737, 2010. 
[10] S. A. Taher and M. H. Karimi, 'Optimal reconfiguration and DG allocation in balanced and unbalanced distribution systems', Ain Shams Eng. J., vol. 5, no. 3, pp. 735-749, 2014.

[11] M. M. Othman, W. El-Khattam, Y. G. Hegazy, and A. Y. Abdelaziz, 'Optimal placement and sizing of voltage controlled distributed generators in unbalanced distribution networks using supervised firefly algorithm', Int. J. Electr. Power Energy Syst., vol. 82, pp. 105-113, 2016.

[12] M. M. Othman, W. El-Khattam, Y. G. Hegazy, and A. Y. Abdelaziz, 'Optimal placement and sizing of distributed generators in unbalanced distribution systems using supervised big bang-big crunch method', IEEE Trans. Power Syst., vol. 30, no. 2, pp. 911-919, 2015.

[13] A. Y. Abdelaziz, Y. G. Hegazy, W. El-Khattam, and M. M. Othman, 'Optimal allocation of stochastically dependent renewable energy based distributed generators in unbalanced distribution networks', Electr. Power Syst. Res., vol. 119, pp. 34-44, 2015.

[14] P. Gangwar, S. N. Singh, and S. Chakrabarti, 'Network reconfiguration for the DG-integrated unbalanced distribution system', IET Gener. Transm. Distrib., vol. 13, no. 17, pp. 3896-3909, 2019.

[15] F. Ding and K. A. Loparo, 'Feeder Reconfiguration for Unbalanced Distribution Systems With Distributed Generation : A Hierarchical Decentralized Approach', pp. 0-9, 2015.

[16] T. Ramana, V. Ganesh, and S. Sivanagaraju, 'Distributed generator placement and sizing in unbalanced radial distribution system', Cogener. Distrib. Gener. J., vol. 25, no. 1, pp. 52-71, 2010.

[17] L. S. Pierezan, J. and Coelho, 'Coyote Optimization Algorithm: A new metaheuristic for global optimization problems', in Proceedings of the IEEE Congress on Evolutionary Computation (CEC), Rio de Janeiro, Brazil, 2018, pp. 2633-2640.

[18] T. N. Ton, T. T. Nguyen, V. A. Truong, and T. P. Vu, 'Optimal Location and Size of Distributed Generators in an Electric Distribution System Based on a Novel Metaheuristic Algorithm', Eng. Technol. Appl. Sci. Res., vol. 10, no. 1, pp. 5325-5329, 2020.

\section{XÁC ĐỊNH VỊ TRÍ VÀ KÍCH THƯớC CỦA DG TRÊN HỆ THỐNG ĐIỆN PHÂN PHỐI KHÔNG CÂN BẰNG HÌNH TIA SỬ DỤNG THUẬT TOÁN COYOTE}

Tóm tắt. Bài báo này đề xuất một phương pháp tối ưu vị trí và kích thước của các nguồn điện phân tán (DG) dựa trên thuật toán Coyote (COA) để giảm thiểu tổn thất công suất của hệ thống phân phối không cân bằng hình tia (URDS). Phương pháp COA được đề xuất là một thuật toán siêu kinh nghiệm được phát triển gần đây, lấy cảm hứng từ cuộc sống xã hội của loài sói Bắc Mỹ. COA không cần sử dụng các tham số điều khiển trong quá trình áp dụng cho bài toán tối ưu. Phương pháp đề xuất, sử dụng $\mathrm{COA}$ nhằm tối ưu lắp đặt DG cho URDS nhằm đem lại tổn thất công suất tác dụng là nhỏ nhất. Kết quả của phương pháp đề xuất được thử nghiệm trên URDS 25 nút và so sánh với một phương pháp khác đã cho thấy hiệu quả của nó đối với URDS.

Từ khóa. Nguồn điện phân tán; Thuật toán Coyote; Hệ thống điện phân phối không cân bằng hình tia; Tổn thất công suất.

Received on: 17/03/2021

Accepted on: 17/07/2021 